\title{
Evidencias mercantiles en contextos arqueológicos mitraicos
}

\author{
Julio Muñoz García-Vaso*
}

Desde que Franz Cumont, «Padre de los Estudios Mitraicos», dictaminara a fines del siglo pasado la prioridad del estamento militar en la introducción y difusión de los Misterios de Mithra' ${ }^{\prime}$ en el Occidente del Imperio, nadie habia sugerido la posibilidad de que otro $u$ otros factores pudieran haber influido en mayor medida en el desarrollo de este fenómeno cultual ${ }^{2}$.

Sin embargo, las recientes revisiones de los testimonios arqueológicos ya existentes del culto de Mithra, así como la investigación de los testimonios descubiertos en las últimas décadas en los antiguos territorios de diversas provincias imperiales, están revelando la presencia de

* Departamento de Prehistoria e Historia Antigua, UNED, Madrid.

- Mysteria Mithrae o Sacra Mithrae son los nombres con los que los contemporaneos denominaron a este culto. No fue hasta el siglo xIx cuando se empezó a usar el término mitraismo, término hoy generalizado en todo el mundo científico, pero que, con su terminación -ismo, se presta con frecuencia a interpretaciones doctrinales erróneas. Solamente dos religiones recibieron en la época de los Misterios de Mithra la terminación -ismus: iudaismus y christianismus. Cfr. S. WIKANDER, Les syncretismes dans les religions grecque et romain, Paris 1973, pág. 10; M. Simon, "Mithra, rival du Christ?". Acta Iranica, 17, Leiden 1978, pág. 461.

${ }^{2}$ F. Cumont, Textes et Monuments figurés relatives aux Mysteres de Mithra, 1-11. Bruxelles 1896-1899; Idem, The Mysteries of Mithra. New York 1956, pág. 79. También sobre el papel desempeñado por el ejército romano en la difusión del mitraismo, cfr. G. WEBSTER. The Roman imperial army of the first and second centuries A.D., London, f.a., pág. 270; L.W. JONES. The cults of Dacia, University of California Publications in Classical Philology, vol. 9, núm. 8, pág. 287; M. J. Vermaseren, "ll culto di Mithra in Germania", Convegno internazionale Renania Romana (Roma 14-16 aprile, 1955), Roma 1976, págs. 136-144: C.M. DANIELS, "The Role of the Roman Army in the Spread and Practice of the Mithraism", Mithraic Studies, vol. II, págs. 249-274. 
elementos civiles y urbanos, con frecuencia mucho más activos que los militares, especialmente los de carácter comercial de procedencia oriental. En tal sentido, es cada vez mayor el número de investigadores que en nuestros dias está llegando a conclusiones radicalmente distintas a las que llegaron Cumont y casi todos sus seguidores. Autores como R-A. Turcan ${ }^{3}$, V. J. Walters ${ }^{4}$, M. M. Alves ${ }^{5}$, Lj. Zotovic ${ }^{6}$, Blawastky y Kochelenko ${ }^{7}$, entre otros, han demostrado de manera concluyente la prioridad de factores, distintos del militar, en la introducción y difusión de este culto en las diferentes provincias occidentales.

Países como el Reino Unido, cuyos especialistas venían atribuyendo tradicionalmente un papel preponderante a las legiones en este fenómeno, sobre la base de la presencia de los mitreos de Borcovicium (Housesteads) ${ }^{8}$, Brocolitia (Carrawburgh) ${ }^{9}$, y Vindobala (Rudchester) ${ }^{10}$ en el limes nórdico, el Vallum Hadriani, se han visto obligados, después del descubrimiento del mitreo de Walbrook, en la City de Londres (la antigua Londinium ", a admitir un marcado carácter "civil» y "urbano", relacionado directamente con los comerciantes orientales, en el mitraismo insular ${ }^{12}$.

Incluso, en Germania, en donde el elemento militar presenta casi exclusividad en el contexto cultual mitraico, también se está comprobando una presencia importante de elementos civiles. Charles Daniells, que localizó 19 ejemplos seguros de santuarios mitraicos y otros proba35.

${ }^{3}$ R. A. Turcan, Les religions de l'Asie dans la vallé du Rhône, Leiden 1972, págs. 34-

${ }^{4}$ V. J. WaLters, The Cult of Mithras in the Roman Provinces of Gaul, Leiden 1974.

5 M. M. Alves, "Os cultos orientais em Pax lulia, Lusitania", Memorias de Historia Antigua, V, 1981, págs. 33-39.

${ }^{6} \mathrm{LJ}$. Zotovic, Les cultes orientaux sur le territoire de la Mésie Supérieure, Leiden, 1966, págs. 6-36

W. BlaWAStKy-G. Kochelenko, Le culte de Mithra sur la côte septentrionale de la mer Noire, Leiden 1966.

${ }^{8}$ R. C. Bosanouet, "Excavations at Housesteads; the temple of Mithras", Archaeologia Aeliana, 2nd series, XXV (1904), págs. 255-263.

${ }^{9}$ I. A. RICHMOND - J.P. GILLAM - E. BIRLEY, "The Temple of Mithras at Carrawburgh", Archaeologia Aeliana, 4th series (1951), págs. 1-52.

${ }^{10} \mathrm{~J}$. P. GILlaM - I. MAC IVOR, "The Temple of Mithras at Rudchester", Archaeologia Aeliana, XXXII (1954), págs. 176-219.

11 J. R. HARRIS, The Oriental Cults in Roman Britain, Leiden 1965, págs. 3-17.

12 I. A. Richmond, Roman Britain, Aylesbury 1963 (2nd. ed.), pág. 212: “The London mithraeum, with its numerous associated deities, is linked with Eastern merchands as well as with veterans, perhaps associated with the garrison of the provincial capital, quartered in the northwest or Cripplegate corner of the Roman city". Cfr. también J. M. C. ToYNBEE, Art in Roman Britain (2nd. ed.), London 1963, págs. 2-3, 132-3, 134-5 y 141-5. 
bles en Renania, fechados en los años centrales del siglo ॥, señala que, en la epigrafía mitraica germánica, las dedicatorias sugieren que las legiones, más que las tropas auxiliares orientales, fueron el elemento difusor de este culto ${ }^{13}$. Pero, aunque a menudo localizadas en emplazamientos militares o hechas por personas relacionadas con el ejército, lo cierto es que también hay un buen número de dedicatorias de civiles ${ }^{14}$, e incluso santuarios mitraicos tan importantes como los de Stockstad y Osterburken parecen haber sido plenamente civiles ${ }^{15}$.

En Dieburg, en Germania Superior, dos artesanos, uno trabajando en un taller de piedras, el otro en un taller de calzado (un galorromano originario del Berry) contribuyen a la ofrenda de una estela doble a Mithra ${ }^{16}$. Porque 10 cierto es que las ciudades con guarnición militar atraen la atención de comerciantes, mesoneros y de otros beneficiados de la clientela militar.

En una provincia tan marcadamente militar como fue Dacia, el hecho de que la mayor parte de los materiales mitraicos fuera descubierta en localidades que surgieron y se desarrollaron en torno a campos de legionarios o de tropas auxiliares, es, sin duda, un poderoso argumento en favor de la contribución del ejército a la propagación de la religión de Mithra ${ }^{17}$. El mitraismo se extendió a lo largo y a lo ancho de esta provincia, en donde llegó a ser, a partir del siglo III, la corriente religiosa local más poderosa. Pero aunque fue adoptado especialmente por el ejército, también tuvo adeptos en amplios circulos de la población civil dacia ${ }^{18}$.

Así pues, en la Dacia, el culto de Mithra ha gozado también de un gran favor y ha conocido una notable difusión en los grandes centros urbanos, como lo atestigua el material arqueológico descubierto.

Unos 101 monumentos epigráficos de la Dacia están dedicados a Mithra. Para hacernos una idea todavía más clara de su difusión territorial, precisaremos que, de esta cifra, 31 piezas han sido descubiertas en el centro militar, económico y administrativo de Apulum (Alba Julia,

13 C. Daniels, Obra citada, págs. 249-274.

${ }^{14} \mathrm{Cfr}$. E. SCHWETHEIM, Die Denkmäler orientalischer Gottheiten im römischen Deutschland, Leiden 1974.

${ }^{15}$ C. Daniels, Obra citada, pág. 273.

16 R-A. Turcan, Mithra et le mithriacisme, Paris 1981, págs. 33-34.

M. MACreA, Viata in Dacia romanâ, Bucuresti 1969, pág. 372.

${ }^{18}$ C. Baluta, "Le Mithriacisme dans l'epigraphie de la Dacie", Acta Iranica, 17, 1978, pág. 1 ss. 
Rumanía), sede permanente de la Legio XIII Gemina, 29 en la capital oficial, Sarmizegetusa, y 25 en otras localidades urbanas o rurales ${ }^{19}$.

Entre los mitreos que existían en Apulum, uno de ellos pertenecía, probablemente, al campo de la colonia Nova Apulensis y sirvió como lugar de culto de los soldados de la guarnición, tal y como se atestigua en la mayor parte de los materiales aquí descubiertos. Pero este mitreo era muy diferente a los de la colonia Aurelia Apulensis, que pertenecían a la comunidad mitraica local, centro de carácter predominantemente comercial, con una población en su mayoría greco-oriental social y étnicamente más heterogénea. Como es de suponer, los monumentos mitraicos militares son cronológicamente más antiguos ${ }^{20}$.

Por todo ello, I. Servan y C. Baluta llegan a la conclusión de que este culto ha sido introducido y difundido en la Dacia por los más variados elementos, sobre todo, comerciantes orientales, miembros del ejército romano y libertos, que desempeñan funciones administrativas, procedentes de Oriente ${ }^{21}$.

Más que cualquier otro culto oriental, el mitraismo es en la Dacia la manifestación de una "moda" de la época, la de la "orientalización" del Imperio romano. Es por ello por lo que está desprovisto de una verdadera base étnico-demográfica y no está en condiciones de aportar indicaciones precisas sobre el origen de sus adeptos o de sus sacerdotes, aunque se haya atestiguado un contexto greco-oriental. Se trata, por consiguiente, de un fenómeno con significación casi exclusivamente cultual y no étnica ${ }^{22}$.

Lo cierto es que la presencia de elementos civiles o urbanos e incluso concretamente mercantiles se ha evidenciado en contextos arqueológicos muy numerosos y dispares de las provincias occidentales del Imperio. $Y$ también se han evidenciado en contextos arqueológicos mitraicos de la misma Roma y de Ostia (donde los mitreos están próximos a las sedes de corporaciones).

19 Cfr. C. Baluta, Obra citada, págs. 1-6.

${ }^{20}$ Cfr. C. Baluta, Obra citada, pág. 6.

21 I. Serban - C. Baluta, “On Mithraism in the army of Dacia Superior", Mysteria Mithrea, Leiden 1979, pág. 578. El mitraismo en la Dacia Inferior presenta las mismas caracteristicas. Cfr. I. BerRIU - C. C. PETOLESCU, Les cultes orientaux dans la Dacie meridionale, Leiden, 1976, pags. 13-19; A. ARICESCu, Armata in Dobrogan romane, Bucuresti 1977, págs. 183-184.

22 C. BALUTA, "Le Mithriacisme dans l'épigraphie de la Dacie", Acta Iranica, 17, Leiden 1978, pág. 6. 
En Roma y Ostia, los mitreos se encuentran con frecuencia en el interior $o$ en las proximidades de termas (Termas de Caracalla, en Roma, por ejemplo ${ }^{23}$ ) y en la vecindad de establecimientos afectos al personal de los juegos circenses (gladiadores, guardias del circo, etc.,) como ocurre en el caso de mitreo del Circo Máximo ${ }^{24}$, también en Roma. Todos ellos demuestran igualmente el impacto del mitraismo en todos los sectores de la sociedad. Fuera de algunos casos particulares, no parece que las comunidades mitraicas se oculten temerosamente en viviendas privadas, al menos, en general. A veces, se instalan directamente en edificios públicos. Pero si en el siglo IV algunos conventículos mitraicos se albergaron en tales casas, es porque sus propietarios eran refractarios a la propagación del cristianismo. Este es el caso del mitreo descubierto cerca de San Martino ai Monti ${ }^{25}$. Particularmente instructivo al respecto es el caso de los fabricantes de estopa de Ostia, que instalaron un mitreo en el siglo III en las criptas de su templo colegial ${ }^{26}$.

Las excavaciones del mitreo de Santa Prisca (Roma) evidenciaron la existencia de grandes edificaciones dedicadas a almacenes. Por otra parte, este mitreo está enclavado en una zona en la que se atestigua la presencia de otros cultos orientales, así como de actividades mercantiles ${ }^{27}$. Los almacenes de vino de la misma Roma también cuentan con uno de estos santuarios (aunque parecen posteriores al mitreo) ${ }^{28}$.

Los santuarios de Mithra en Ostia están instalados en edificios preexistentes - almacenes, termas, otros edificios públicos y privados-, eligiendo las habitaciones más oscuras (u obscureciéndolas mediante la obstrucción de las fuentes de iluminación), preferentemente subterráneas, porque, como es sabido, el santuario debía imitar el spelaeum, la caverna en la que Mithra nació ${ }^{29}$.

${ }^{23}$ D. M. Cosı, "ll mitreo nelle Terme di Caracalla", Mysteria Mithrae, Leiden 1979, págs. 931-942.

${ }^{24}$ R-A. Turcan, Mithra et le mithriacisme, Paris 1981, pág. 34.

${ }^{25}$ R-A. TURCAN, Ibídem.

${ }^{26}$ R-A. TURCAN, Obra citada, pág. 33.

${ }^{27} \mathrm{Cfr}$. M. J. Vermaseren - CC. VAN ESSEN, Excavations at the Mithraeum of the Church of St. Prisca at Rome, Leiden 1965, págs. 107 y ss.

${ }^{28}$ Cfr. D. Gallo, "ll mitreo di San Silvestre in Capite", Mysteria Mithrae, Leiden 1979, pág. 242.

${ }^{29}$ M. Floriani Souarciapino, "Les cultes orientaux", Histoire et Archeologie (Dossier "Ostie Port de Rome»), núm. 71, marzo, 1983, pág. 68. 
Los mitreos descubiertos en Ostia son $18^{30}$. Los edificios relacionados con estos mitreos y cuya función es identificable con ellos son todos o casi todos de carácter público. Resulta así confirmada la observación de Becatti a propósito de los mitreos de Ostia en el sentido de que nunca - casi nunca estos santuarios están integrados en casas particulares, sino en edificios de carácter público ${ }^{31}$.

Los cultores mitraicos de Pax lulia (Beja, Portugal) presentan una variante especifica que ha sido bien estudiada por M. M. Alves. Su mitraismo, según esta autora, no parece tener respaldo directo en la religiosidad de los sectores comerciales -prácticamente inexistentes en este lugar-, pero tampoco en los militares - también inexistentes-, sino en los de una clase media surgida de la industria, concretamente de la industria extractiva minera ${ }^{32}$.

En la Galia, en donde la abundancia de cognomina griegos hace pensar en los comerciantes como introductores de este culto ${ }^{33}$, se produce un fenómeno de penetración del mitraismo paralelo al de Hispania, al que luego nos referimos. Por ejemplo, en Aquitania, en Elusa (Eauze, en el Gers), el jefe de la comunidad mitraica es un mercader de ropas, originario de Tréveris ${ }^{34}$.

El responsable de una comunidad mitraica en Vien-en-Val-Romey (Ain) era un médico que ejercía su sacerdocio en relación con la explotación de una instalación termal y un culto a las fuentes ${ }^{35}$.

Otro de estos uestiarius se da a conocer como mitraista en la Mesia Superior, concretamente en Viminacium (Kostolac, Yugoslavia) ${ }^{36}$, provincia en la que $\mathrm{Lj}$. Zotovic ha demostrado que las legiones romanas no fueron las portadoras de este culto ni a ella ni a las provincias limitrofes ${ }^{37}$. Incluso en Poetovio en Panonia, los seguidores de Mithra son empleados del publicum portorium ${ }^{38}$.

${ }^{30}$ Cfr. F. ConRell, «Topografía Mitraica”, Mysteria Mithrae, Leiden 1978, pág. 79.

31 Cfr. G. Becattı, Scavi di Ostia, II, I Mitrei, Roma 1954, pág. 133 ss.

32 Cfr. M. M. Alves, Obra citada, págs. 33-39.

$33 \mathrm{Cfr}$. V. J. WaLters, The cult of Mithras in the Roman Provinces of Gaul, Leiden 1974, pág. 31ss., espec. pág. 35 (de 60 dedicatorias, solamente hay 4 de militares); C. B. PASCAL, "The Cults of Cisalpine Gaul», Col Latomus, 75, Bruselas 1964, pág. 61.

${ }^{34}$ R-A. TuRCan, Obra citada, pág. 33.

35 R-A. TuRCan, Obra citada, pág. 34.

36 R-A. TuRCAN, Obra citada, pág. 33.

37 LJ. Zotovic, Obra citada, pág. 33: “Outre ce dernier monument, posé par un véteran, il n'existe en Mésie Supérieure aucune dédicace faite par des soldats. II n'est de même 
En Intercisa (Dunapentele, Hungría) y en Koenigshoffen, cerca de Strasbourg, el mithreo está instalado en el barrio civil y comercial de los canabae (almacenes) ${ }^{39}$.

En un contexto arqueológico no occidental, el mitreo de Cesarea Marítima (Siria), ciudad que durante casi 600 años fue puerto y capital de la provincia romana y bizantina de Siria Palestina, se aloja en uno de los nueve cobertizos portuarios para cereales que se están excavando actualmente en este lugar. Se ha fechado en el siglo III o con anterioridad ${ }^{40}$.

Turcan no duda en asegurar que, tanto en Londres, como en Mérida, como en Arlés, es este tipo de hombres de negocios, aparentemente orientales helenizados, el que ha financiado la decoración de los santuarios ${ }^{41}$.

También para Hispania, numerosos autores, siguiendo a Cumont, han venido aceptando tradicionalmente el protagonismo de los militares en la introducción y difusión de este culto, circunstancia que, juntamente con la de ser Hispania una provincia pacata, les ha servido para explicar una supuesta reducida penetración del dios iranio en ella ${ }^{42}$. Sin embargo, investigaciones más recientes han demostrado la inexactitud de este planteamiento. Dos hechos han permitido confirmar esta inexactitud.

En primer lugar, se ha comprobado que la concentración geográfica de testimonios de este culto no se registra, como aseguraba A. Garcia y Bellido, en las regiones más militarizadas y menos romanizadas del NO y SO peninsulares ${ }^{43}$. El reciente descubrimiento de nuevos testimonios

dans les provinces limitrophes; l'armé n'était donc pas le porteur du culte de Mithra en cette province".

${ }^{38}$ E. WILL, "Les fidèles de Mithra à Poetovio", Adriatica Praehistoria et Antigua (Misc. G. Novak dicata), Zagreb 1980, págs. 633-634.

${ }^{39}$ R-A. TuCAN, Obra citada, pág. 34.

${ }^{40}$ Cfr. R. J. BuLl, "The Mithraeum at Caesarea Maritima", Acta Iranica, 17, Leiden 1978 , págs. 75 ss.

41 R-A. TURCAN, Obra citada, pág. 34.

${ }^{42}$ F. Cumont, The Mysteries of Mithra, New York 1956, pág. 79: "Mithraic monuments are almost completely missing in the central and western parts of Gaul, in the Spanic Peninsula, and in the South of Britain, and they are rare even in the interior of Dalmatia. In these places also no permanent army was estationed; there was consecuently no importation of Asiatics; while there was also in these countries no great center of international commerce to attract them". Los errores de apreciación en los que incurre Cumont son evidentes y no requieren comentarios.

43 A. Garcia y BeLLIDO, "El culto de Mithras en la Península Ibérica", Boletín de la Real Academia de la Historia, CXXII, 1948, págs. 293-298 y 313 ss.; idem, Les Religions Orientales dans l'Espagne Romain, Leiden 1967, págs. 21-26. 
en zonas costeras, sobre todo, mediterráneas, ha contribuido también a permitir un planteamiento de signo inverso ${ }^{44}$. Por otra parte, se ha evidenciado que incluso localidades de la importancia similar de Asturica Augusta, Legio, Lucus Augusti, etc., no han aportado - al menos hasta la fecha - testimonio alguno de culto mitraico.

En segundo lugar, también se ha comprobado que el porcentaje epigráfico de dedicantes hispanos pertenecientes al ejército es, contrariamente a lo que cabría esperar en el caso de haber sido las legiones las introductoras de este culto, prácticamente nulo. De las 33 inscripciones mitraicas existentes en la Península ${ }^{45}$, solamente una, fechada en 155 d.C., procedente de Emerita Augusta, parecer pertenecer a un militar de la Legio VII Gemina ${ }^{46}$. Pero incluso en este caso, el dedicante, Marco Valerio Segundo, desempeña un empleo tan ambiguo, desde el punto de vista de la estructura organizativa castrense, como es el de frumentarius. Este empleo, como muy bien ha señalado la autora portuguesa M. M. Alves, podria incluso carecer de connotaciones militares ${ }^{47}$. Otros dos posibles casos de presencia militar en contextos epigráficos mitraicos son de muy difícil comprobación ${ }^{48}$.

Prescindimos, intencionalmente, por razones obvias de las evidencias epigráficas de Aquileia ${ }^{49}$ y de Slaveni, en la Dacia Meridional ${ }^{50}$, en

${ }^{44}$ Los descubrimientos más recientes se han efectuado en el litoral catalán. Entre los cultos orientales, el que gozó de mayor favor en dicha zona fue el de Mithra, atestiguado en Tarraco, Barcino, Baetulo y Cabrera de Mar (Mataró). Cfr. S. MARINER, "Nuevos testimonios de culto mitraico en el litoral de la Tarraconense", Segundo Congreso internacional de Estudios sobre las culturas del Mediterráneo Occidental (Barcelona, 1975), Barcelona 1978, págs. 79-84; idem, Quaderns de Prehistória i Arqueología del Maresme, 8-9 (1979), págs. 274-276, con fotografía y dibujos; G. FABRE, M. MAYER, I. RODA, Inscripcions romanes de Mataro i la seva area (Epigrafía Romana del Maresme), Mataró 1983; I. Roda, "Las dedicatorias a divinidades en la Barcelona romana", La religión romana en Hispania, Madrid 1981, págs. 25-40. Para la costa atlántica bética, cfr. J. BeLtRAN-M. L. LOZA, “El culto mitraico en la costa atlántica bética: un nuevo testimonio en Barbate (Cádiz)", Actas del Congreso Internacional del Estrecho de Gibraltar, Noviembre, 1987, Ceuta, págs. 833-836.

45 J. MuNoz, El culto de Mithra en Hispania: caracteres especificos, (Tesis Doctoral, inédita), UNED, Madrid 1989, págs. 863-864.

${ }_{46}$ Sobre la dedicatoria de Marco Valerio Segundo, cfr. Vermaseren, CIMRM, I, pág. 276, núm. 793; A. Garcia y Bellido: ROER, pág. 27.

${ }_{47}$ M. M. Alves, Obra citada, p. 35.

${ }^{48}$ Para el primer caso, cfr. Fouilles de Connimbriga, II (1976), pág. 25, núm. 7 y A. Garcia y Bellido, ROER, pág. 29, núm. 7; para el segundo, A. Garcia y Bellido: «El culto de Mithra en la Península lbérica», pág. 300, núm. 2 y ROER, pág. 21. En el primer caso se cita una inexistente centuria y en el segundo el dedicante no parece ser un militar, sino un dunviro.

${ }_{49}$ Para Aquileia, cfr. CIL V, 806; Vermaseren, CIMRM, núm. 744.

so Para Slaveni, cfr. I. Berciud - C. C. Petolescu, Obra citada, pág. 53, núm. 56. 
las que sí se registra la consagración a Mithra de soldados hispanos, en el segundo caso encabezados incluso por sus principales.

Este nuevo planteamiento obliga, ante todo, a reducir la importancia del papel atribuido al ejército en la introducción y difusión del mitraismo en Hispania. Pero, sobre todo, a tratar de identificar el factor o los factores civiles y urbanos que pudieron ser las causas primarias de este fenómeno cultural. En tal sentido, ha sido el análisis cuantitativo y cualitativo de los testimonios arqueológicos y epigráficos de este culto en sus correspondientes coordenadas de espacio y tiempo, lo que mejor ha conducido a la identificación de tales factores ${ }^{51}$.

La distribución geográfica de los testimonios arqueológicos y epigráficos de este culto (Mapa 1) confirma, por un lado, la concentración de

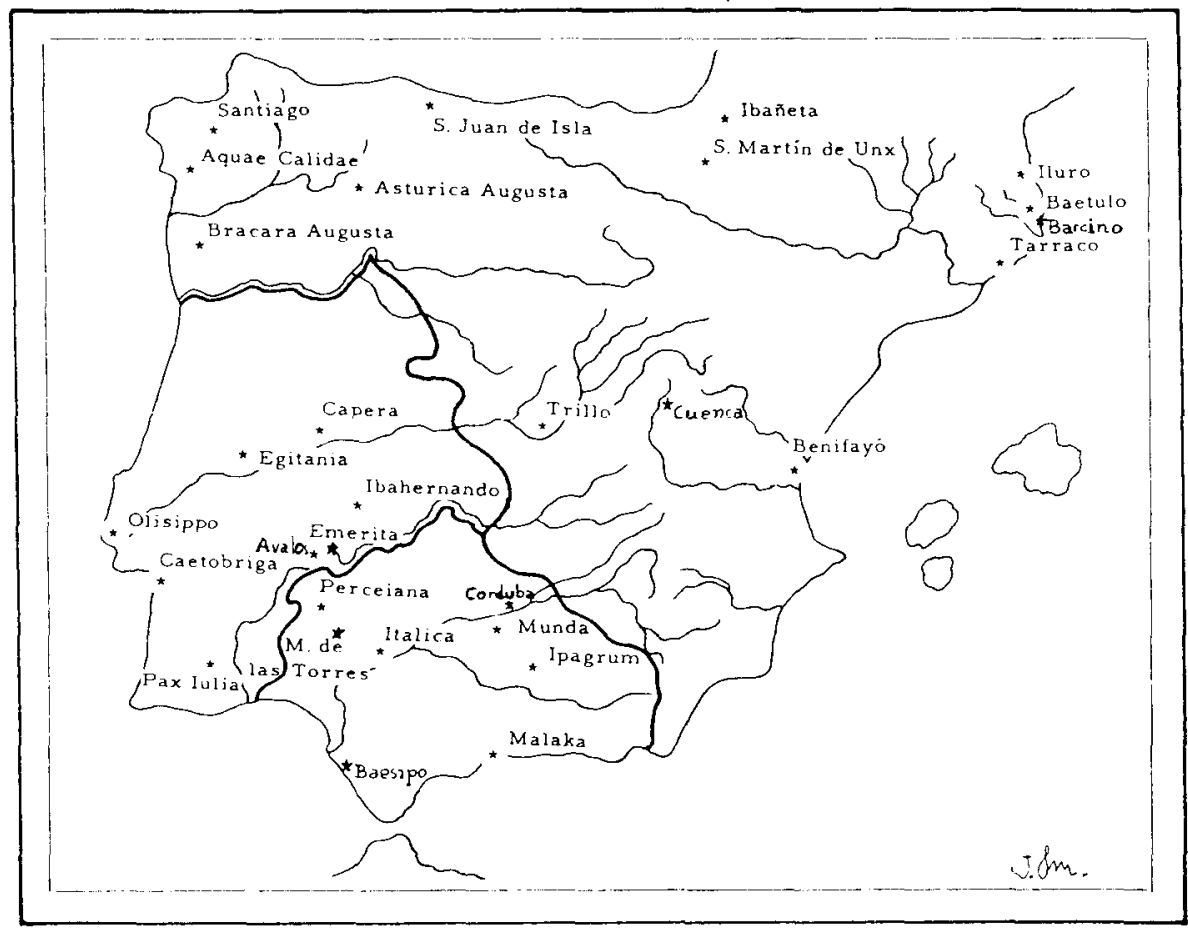

Mapa 1. Distribución geográfica de testimonios arqueológicos mitraicos en la Península Ibérica (siglos II-IV) (J. Muñoz)

51 J. Muñoz, Obra citada, págs. 645 ss y 685 ss. 
los mismos en las zonas más romanizadas y menos militarizadas de la Península, tales como Cabrera de Mar (Mataró), Baetulo, Barcino, Tarraco, Benifayó, Malaca, Baesipo, Caetobriga, etc., que fueron en su mayoría puertos marítimos de primer orden durante el Alto Imperio, asi como también en Corduba, centro comercial de primera categoria, Italica, también importante, y en la misma Emerita Augusta.

Exceptuando estas localidades, la presencia de testimonios arqueológicos de este culto se documenta en puntos aislados, tales como Medina de las Torres, localidad situada dentro del foco de irradiación mitraica emeritense ${ }^{52}$, Caldas de Reyes (Aquae Calidae) y San Juan de Isla, debidos, supuestamente, a influencia militar, aunque las inscripciones de ambos lugares no nos revelan nada acerca de sus correspondientes dedicantes ${ }^{53}$; los enclaves nórdicos del Alto de Ibañeta y de San Martín de Unx, en Navarra, con una onomástica de origen renano o danubiano, traida tardiamente por laetes o limitane ${ }^{54}$, y quizás también en Cuenca, en donde el muy mutilado tronco de un Aion, divinidad importante en los Misterios de Mithra, sugiere la existencia de este culto ${ }^{55}$.

Se ha comprobado, igualmente, que la mayoría de los puntos de procedencia de testimonios arqueológicos mitraicos son periféricos y concretamente, costeros. $Y$ también se ha comprobado que muchos de estos puntos fueron los lugares preferidos de asentamiento - bien documentados por la arqueologia y la epigrafia - de comerciantes forasteros avecindados en Hispania (Mapa 2) muchos de ellos libertos de origen oriental ${ }^{56}$.

Por lo que respecta a los datos cronológicos del mitraismo hispano, hay que señalar que son bastante escasos e inseguros, con la muy notable excepción de los aportados por los testimonios arqueológicos y epigráficos procedentes del mitreo de Emerita Augusta.

Contamos con un conjunto de monumentos, procedentes de Emerita Augusta, que se pueden fechar con exactitud en el año 155 d.C. (Anno

${ }^{52}$ C/L II y Suppl. 1025; CUMONT, MMM, I, 581.

${ }^{53}$ CIL II y SUppl. 5625; CuMONT, MMM, II, 513.

${ }_{54}$ Ambas inscripciones en C. Castillo - J. Gomez - M.D. Mauleon, Inscripciones romanas del Museo de Navarra, Pamplona 1981, núm. 23, págs. 50-51, lám. XXIII (Alto de Ibañeta) y núm. 31, pág. 57 (San Martín de Unx). Cfr. tambièn J. MuÑoz, Obra citada, pags. 664-671.

${ }_{55}$ J. MuNOz, Obra citada, núm. 9, en pág. 676.

56 J.M. BlazQuez, La Romanización, II, Madrid 1975, pág. 210. En Málaga, por ejemplo, hay documentada una comunidad de sirios y asiáticos, dedicados a la exportación de minerales y salazones. 


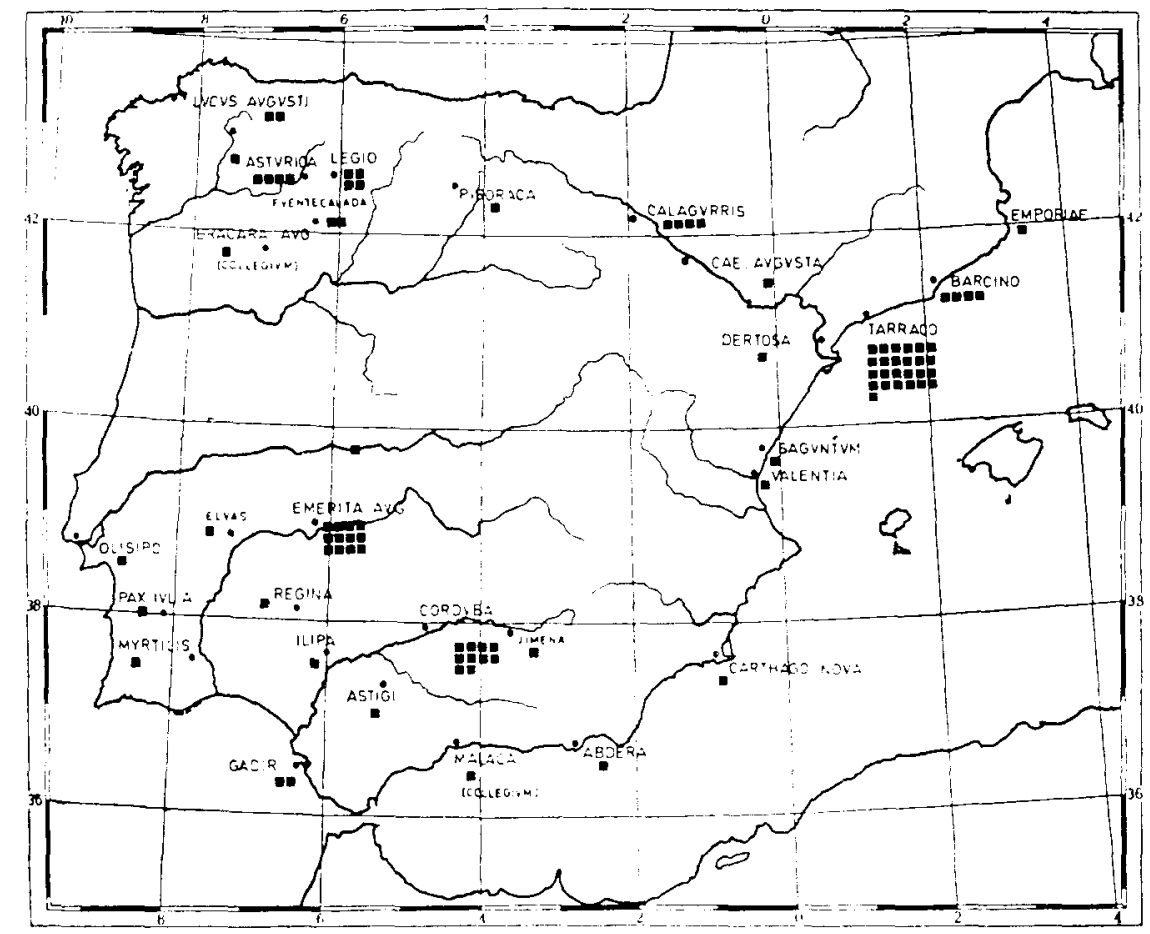

Mapa 2. Lugares de Hispania con «testimonios de forasteros» (según A. Garcia y Bellido)

Coloniae CLXXXX) ${ }^{57}$. Es, por consiguiente, un hecho evidente que, a mediados del siglo || d.C., existe una comunidad mitraica que hubo de ser fundada con anterioridad al mismo año 155 , como ya había señalado A. García y Bellido ${ }^{58}$. Según J. Alvar, la fecha inaugural de este mitreo no puede ser anterior a dicho año si se tiene en cuenta la ausencia de testimonios previos a la gran explosión cultual que se registra en esta fecha, y si se acepta la expresión epigráfica ara genesis invicti Mithrae no sólo como la petra genesis, sino también como alusión al ara inaugural del mitreo emeritense, que habría sido fundado, por consiguiente,

57 Este conjunto de monumentos fue publicado casi en su totalidad por J. R. MELIDA, "Los cultos emeritenses de Serapis y Mithras", BRAH, 1914, págs. 439-446 (con 8 láms.), pero, sobre todo por A. GarCla y BELLIDO, Obra citada, 1948, págs. 313-349 (con 18 láms.).

58 A. Garcia y Bellido, Obra citada, pajg. 320 
en el año 155 d.C., aunque reconoce que esta interpretación es demasiado débil ${ }^{59}$. Efectivamente, lo es, puesto que, en el contexto cultual mitraico, la expresión ara genesis no es sino una alusión al altar dedicado por un iniciado al dios de los misterios, para agradecer su propio renacimiento, mediante la iniciación, a una nueva vida ${ }^{60}$. De aquí, también el uso del término renatus en algunos contextos epigráficos mitraicos ${ }^{61}$.

De Emerita Augusta tenemos otros testimonios datables igualmente en la segunda mitad del siglo II. Estos son, según J. Alvar, los monumentos mitraicos más antiguos de la Peninsula Ibérica ${ }^{62}$. Otras fechas más o menos seguras son las del relieve mitraico de Caetobriga (Troya, Portugal), datado en el siglo III d.C. por A. García y Bellido ${ }^{63}$, al igual que la inscripción de San Juan de Isla, que sería de fines del mismo siglo ${ }^{64}$. A estas fecha más o menos seguras añade el citado autor otras dudosas, como la del relieve de Emerita Augusta que representa un banquete ritual, que podria fecharse en el siglo IV d.C. ${ }^{65}$ y el famoso Mosaico Cosmogónico de la misma procedencia, que, según opinión reciente, podría pertenecer al mismo siglo, aunque generalmente se viene admitiendo las del siglo II o comienzos del III como fechas más probables de su realización ${ }^{66} \mathrm{e}$ incluso las de finales del siglo 1 y comienzos del $11{ }^{67}$.

El ara mitraica de Benifayó ${ }^{68}$, si bien pudiera testimoniar una vez más el específico carácter colectivista del mitraismo hispano ${ }^{69}$, también podría denotar su pertenencia al período en el que el sistema económico

59 J. Alvar, "El culto de Mitra en Hispania», Memorias de Historia Antigua, V (1981), pág. 61.

${ }^{60}$ Cfr. J. MuNoz, Obra citada, pág. 722, notas 6 y 7 , y pág. 723, notas 8 y 9 .

${ }^{61} \mathrm{Cfr}$. U. BIANCHI, "The religio-historical question of the Mysteries of Mithra", Mysteria Mithrae, Leiden 1979, pág. 3 ss.

62 J. Alvar, Obra citada, pág. 61.

63 A. Garcia y Bellido, ROER, pág. 37.

${ }^{64} \mathrm{CIL} \mathrm{II,} 5728$.

${ }^{65}$ Para el relieve del banquete ritual, cfr, H. SCHLuk - TH. Haushild, Hispania Antigua, Meinz 1978, pág. 141, fig. 85. Estos autores los consideran paleocristiano.

${ }_{66}$ A. Blanco, Corpus de Mosaicos romanos de España: Los mosaicos romanos de Mérida, Fasc. I, Madrid 1978, p. 17. Ctr. también J. ARCE, "Mérida tardorromana", Homenaje a Sáenz de Buruaga, Madrid 1982, págs. 209-226 y, sobre todo, J. M. Blazouez, "Cosmología mitraica en un mosaico de Augusta Emerita", Archivo Español de Arqueologia, 59, (núms. 153-154), 1986, pág. 92, ก. 2.

${ }_{67}$ Cfr. H. H. QuET, La mosäique cosmologique de Mérida, pág. 7.

${ }^{6 B}$ Para el ara mitraica de Benifayó, cfr. A. GARCIA Y BELLIDO, "El culto de Mithra", núm. 4; Ídem ROER, núm. 23.

${ }^{69}$ Sobre el carácter colectivo del mitraismo hispano, cfr, J. MuÑOz, Obra citada, págs. 946-950. 
esclavista está transformándose, y ser simplemente la donación de un esclavo, Lucano, dotado de peculium, efectuada tardíamente en el siglo III o en el iv ${ }^{70}$. Como se sabe, muy cerca de Benifayó en Valentia, la actual Valencia, se documenta la existencia de un colectivo cultual constituido por esclavos domésticos, que, según parece, también tienen capacidad económica para efectuar una dedicatoria a Isis $^{71}$.

De cualquier modo, es evidente que la cronología aportada por los testimonios arqueológicos del culto mitraico demuestra claramente, sobre todo en la Bética, y más aún en la Lusitania, la absoluta coincidencia existente entre el desarrollo económico peninsular y el auge del mitraismo hispano ${ }^{72}$.

Este auge del mitraismo hispano, cuyo mejor exponente lo constituye la serie de testimonios arqueológicos del mitreo emeritense, coincide plenamente, como decimos, con una muy positiva conyuntura económica hispana. Se documenta ahora, en el siglo II d.C., un desarrollo económico bético sobre la base del aceite, los minerales y el garum ${ }^{73}$. También se documenta ahora un desarrollo económico lusitano basado en la explotación de cereales, vid y olivo ${ }^{74}$.

Se documenta igualmente la navegabilidad comercial de nuestros rios $^{75}$, asi como los contactos comerciales con puertos orientales ${ }^{76}$, las exportaciones hispanas y las importaciones de algunas manufacturas suntuarias en fletes de retorno ${ }^{77}$.

70 J. Fernandez Ubiña, La crisis del siglo III y el fin del mundo antiguo, Madrid 1982 , pág. 98 .

71 Sobre el sodalicium vernarum colentium Isidem cfr. ClL II, 3730, Suppl. 6004; VID MAN, Siris, pág. 322, núm. 762, y J. M. SANTERo, Asociaciones populares en Hispania Romana, Universidad de Sevilia, 1978, pág. 47.

72 J. MuÑoz, Obra citada, pág. 872-874.

73 Sobre el desarrollo económico bético, cfr. J. M. BLazquez: La Romanización, II, Madrid, 1975, págs. 189 y ss.; Ídem: Economia de la Hispania romana, Bilbao 1978, págs. 485-515; J. Fernandez UBiña, "La crisis del siglo Ill en la Bética", Est. de Hist. Antiqua, V, Granada 1981. Sobre producción y comercialización del aceite bético, cfr. M. PONSICH, $R e-$ chérches archeológiques dans le Bas-Guadalquivir, Paris 1973.

74 Para el desarrollo económico lusitano, cfr. J. M. BlazouEz, La Romanización, II, págs. 189 ss.; Ídem, Economia de la Hispania romana, págs. 570-586.

${ }^{75}$ Sobre la navegabilidad comercial de rios españoles, cfr. A. BALIL, Historia social y económica. La España romana (siglos (-III), Madrid 1975, págs. 85-103; A. GARCiA BELLIDO, "La navegabilidad de los ríos de la Península en la Antigüedad", en Investigaciones Progreso, XVI (1945), págs. 115-122.

76 Para el comercio con puertos orientales, cfr. A. BALIL, Obra citada (Capitulo IV: «EI Comercio", págs. 85-103.

77 Sobre las relaciones comerciales hispanas con Roma y Ostia, cfr. A. BALIL, "Hispania y Ostia", AEA, 33 (1960), págs. 215-217; M.F. SQuarciaPinO, "Cultura artistica di Merida romana", Homenaje a Sáenz de Buruaga, Madrid, págs. 33-52. 
$\mathrm{Si}$, como ha demostrado J. Fernández Ubiña, «los rasgos de apariencia estrictamente religiosa... en realidad forman parte de los fundamentos socioeconómicos de la Bética" ${ }^{78}$, no vemos obstáculo alguno para aplicar, también en el caso del mitraismo, esta misma interpretación e incluso extrapolarla a otras provincias, especialmente a la Lusitania.

En esta favorable coyuntura económica, la función desempeñada por los comerciantes es evidente, ya que, como ha señalado K. Polanyi, la importancia de la redistribución en la última época del Imperio es decisiva ${ }^{79}$. El comercio está en manos de las altas capas sociales 0 de las más ínfimas, pero nunca de las intermedias, hecho que, en nuestra opinión, explica el esplendor del mitraismo emeritense, testimoniado por la prestancia de los materiales arqueológicos proporcionados por su mitreo, sin duda, uno de los más importantes del Imperio romano ${ }^{80}$.

Por otra parte, también la onomástica registra en este mismo período de auge del mitraismo en Hispania el fenómeno del crecimiento del número de libertos orientales, muchos de ellos enriquecidos, sobre todo, por el comercio ${ }^{81}$. Estos, juntamente con los magistrados municipales, integran la burguesía municipal, residente y vinculada a las ciudades ${ }^{82}$. En la misma epigrafía mitraica hispana el porcentaje de libertos es notorio, un 20,67 por 100 , aproximadamente ${ }^{83}$.

Frente a otras provincias del Imperio en las que la epigrafía mitraica no ha permitido identificar el origen de las jerarquias de este culto, en Hispania, el 100 por 100 de las citadas jerarquias demuestra su origen 0 procedencia oriental y en algunos casos su condición de libertos. Son los Hedychro, los Artemidoro, etc. Y esto, sin duda, corrobora aún más no

78 J. FERNANDEZ UBINAa, Obra citada, pág. 131

${ }^{79} \mathrm{~K}$. POLANY, "La economia como actividad institucionalizada», en K. POLANYI ET AL. Comercio y mercado en los Imperios antiguos, Barcelona 1976, págs. 286-316, esp. pág. 311.

Ba Varios autores coinciden en el hecho de que el mitreo de Emerita Augusta fue uno de los más importantes del Imperio. Cfr. A. M. AlvEs, Obra citada, pág. 35; H. VON GALL, "The Lion-Headed and the Human-Headed God in the Mithraic Mysteries", Acta Iranica, 17, Leiden 1978, pág. 521

${ }^{8} 1$ El crecimiento del número de libertos está atestiguado por la epigrafía de este período, Cfr. J.F. Ubiña, Obra citada, pág. 100; A. Balil, pág. 41: J. M. Serrano, Status y promoción social de los libertos en Hispania Romana, Univ. de Sevilla, Sevilla, 1988, págs. 205-219. Las comunidades sirias y orientales de diversa procedencia fueron muy numerosas, en todo Occidente, perdurando hasta época visigoda. Cfr. BLAZOUEZ, J. M. ", "La sociedad del Bajo Imperio en la obra de Salviano de Marsella" en su Discurso de recepción en la Real Academia de la Historia. Madrid, febrero, 1990.

82 J. FernandeZ Ubiña, Obra citada, págs. $10 \nmid$ y 140.

83 J. Muñoz, Obra citada, pág. 895. 
sólo la hipótesis de la presencia del elemento mercantil oriental en el desarrollo del fenómeno cultual mitraico en Hispania, sino de todo un contexto cultual de esta naturaleza ${ }^{84}$.

El mitraismo hispano del siglo $\|$ d.C. es, sin duda alguna, un culto organizado (o sea, estructurado y jerarquizado, como lo demuestra el hecho de que las jerarquías aludidas en los epígrafes sean las de más alto rango lo que implica la existencia de todas las de rango inferior) por libertos, enriquecidos por el comercio, pertenecientes a la burguesía municipal, residentes y vinculados a las ciudades y a sus gobiernos.

Las fechas de desaparición del culto de Mithra en Hispania no las conocemos con exactitud. El monumento más reciente, de entre los fechados, parece ser, según J. Alvar, de finales del siglo III d.C. y de los no fechados, sólo el relieve emeritense del banquete ritual tiene «aspecto" de ser posterior ${ }^{85}$. Existen, sin embargo, fechas posteriores a las que luego nos referiremos.

Es curioso, por otra parte, señala el autor citado, que el resto mitraico más moderno sea el de San Juan de Isla, en un lugar aislado, lejos de cualquier otro centro mitraico, como una especie de reliquia en el extremo norte peninsular ${ }^{86}$. En nuestra opinión, la aparición de este testimonio en dicho lugar no tiene nada de curioso, y está en relación causal con la presencia de testimonios de este culto en los enclaves nórdicos del Alto de Ibañeta y de San Martín de Unx, en Navarra, que responden, a juzgar por la onomástica consignada en ellos, a la tardía presencia en estas regiones nórdicas hispanicas de elementos mitraicos danubianos y renanos asentados como laetes o limitanei en castellae u otros puntos defensivos estratégicos ${ }^{87}$. La cronología de estos testimonios hay que situarla quizás entre finales del siglo III y comienzos del siglo IV.

Los últimos brotes de culto mitraico, según J. Alvar, pudieron haber tenido lugar entre los años 360 y 362, durante el principado de Juliano, en que Pretextato es consularis Lusitaniae y reside, por consiguiente, en Emerita Augusta ${ }^{88}$. Ciertamente, según J. Arce, este es el momento en

${ }^{84}$ J. MuÑoz, Obra citada, págs. 950-951.

85 J. Alvar, Obra citada, pág. 62.

${ }^{86} \mathrm{~J}$. Alvar, Ibídem.

${ }_{87}$ J. MuNNoz, Obra citada, págs. 876-877. Cfr. A. J. Dominguez, “Los ejércitos regulares tardorromanos y el problema del pretendido "limes hispanus" en Revista de Guimaraes, vol. XClll, 1983, Guimaraes, págs 101-128 (con 2 mapas).

${ }_{88} \mathrm{~J}$. AlVAR, Obra citada, pág. 62. 
el que se revitalizarian los cultos paganos, entre ellos el de Mithra ${ }^{89}$. A este "resurgimiento" correspondería, señala J. Alvar, la realización del relieve que representa un banquete ritual y el Mosaico Cosmogónico ${ }^{90}$. Pero no parece que la efímera presencia del Pretextato en Emérita Augusta e incluso la del mismo Juliano al frente del Imperio sean argumentos suficientes para admitir tan notable resurgimiento del culto mitraico en esta colonia. Por otro lado, parece arriesgado no sólo fechar el relieve del banquete ritual y el mencionado mosaico en los años 360 a 362, sino ni siquiera suponerles carácter mitraico.

En cualquier caso, lo cierto es que, como Albertini ha demostrado, la crisis económica del siglo III afectó mucho más a la circulación que a la producción ${ }^{91}$ con lo que habria que matizar el verdadero alcance de lo que se entiende por crisis en esta época, en la que, como ya indicó Vázquez Hoys, A. M. ${ }^{2},{ }^{92}$ en su estudio sobre el culto a Júpiter en Hispania, en éste y en otros cultos romanos en la Península, hay una auge de la epigrafía religiosa dedicada por clases sociales bajas, sobre todo esclavos y libertos. $Y$ en tal sentido, el declive del mitraismo hispano, respaldado en gran medida por los comerciantes orientales, es también un hecho perfectamente explicable.

En resumen, el elemento militar debió desempeñar un modesto papel en la introducción de este culto en Hispania, mucho menos importante, desde luego, de lo que hasta ahora se ha supuesto, e incluso quizás protagonizado únicamente por algunos de los veteranos asentados en las distintas colonias y municipios. Pero, aunque éstos pudieran representar los primeros contactos de Hispania con devotos de la religión de Mithra, nada atestigua, desde un punto de vista estrictamente religioso, que existiese un culto organizado. Es decir, esta primera época, quizás correspondiente a la primera mitad del siglo ॥ d.C., sería la de un culto de mitraistas practicado por mitraistas, pero no la de un culto mitraico practicado por mitraistas, que implicaría la existencia de esa organización y jerarquización a la que antes nos referimos, pero de la que no tenemos noticia ni testimonio alguno hasta la época del auge del mitraismo emeritense, ya en la segunda mitad de dicho siglo.

89 J. ARCE, El último siglo de la España romana: 284-409, Madrid 1982.

90 J. Alvar, Ibídem. Cfr. J. M. Blazouez, "Cosmología mitraica en un mosaico de Emerita Augusta, AEspA, 153-154 (1986), págs. 86-100.

${ }_{91}$ AlBeRTIN, E., L'Empire romain, págs. 305-306.

92 VAzQuez Horos, A. M. ${ }^{\text {a }}$ " "El culto a Júpiter en Hispania", en Cuadernos de Filologia Clásica, XVIII, 1982, pags. 83-205. 
El auge del mitraismo hispano y el desarrollo económico de esta provincia son plenamente coincidentes en sus coordenadas de espacio y tiempo. Y esta coincidencia es uno de los más sólidos argumentos para atribuir un papel prioritario en el desarrollo de este fenómeno a los comerciantes orientales asentados en Hispania, así como un papel secundario a los representantes del estamento militar. Los años centrales del siglo ॥ d.C. constituyeron, sin duda, la etapa de esplendor del mitraismo hispano, atestiguada por la singular prestancia del mitreo de Emerita Augusta.

Un tercer factor importante, según J. Alvar, junto al militar y al comercial, aunque no cuantificable, tuvo que ser cierto espíritu provinciano de imitación a la metrópoli imperial, donde ya Mithra contaba con numerosos adeptos. Esta actitud, según el autor citado, puede contemplarse, más que en el ámbito geográfico, en el social, siendo las áreas geográficas más influidas por este carácter imitativo las más romanizadas, es decir, el $\mathrm{O}$ de la Bética y el $\mathrm{S}$ de la Lusitania, donde se encuentran los centros más importantes: Emerita, Italica, Corduba, Igabrum, Caetobriga, $y$ otros de segundo rango, desde el punto de vista mitraico, como Pax lulia, Medina de las Torres, Malaca ${ }^{93}$.

En nuestra opinión, también en el ámbito topográfico urbano se manifiesta claramente ese espíritu (¿provinciano?) de imitación en el contexto mitraico. La posible ubicación del mitreo emeritense sobre el Cerro de San Albin es asombrosamente igual a la del mitreo de Santa Prisca sobre el Aventino. Pero recordaremos que también la remodelación de éste reproduce fielmente el trazado del mitreo «delle pareti dipinte» de Ostia, como ya señalaron sus excavadores M. J. Vermaseren y CC. Van Essen ${ }^{94}$.

La siguiente fase de la evolución del mitraismo en Hispania, sería la ya apuntada de su decadencia en el siglo III d.C., coincidente también plenamente con la crisis económica que se refleja en la producción, pero sobre todo, en la circulación de productos, de la Bética y la Lusitania. Por ello, cuando el mitraismo está registrando sus mejores etapas de auge en otras provincias, es decir, en el siglo III, en Hispania se está extinguiendo, carente ya del respaldo económico de los comerciantes

93 J. Alvar, Obra citada, pág. 60.

${ }_{94}$ M. J. Vermaseren, CimRM, I, núm. 264; M. J. Vefimaseren - CC. Van Essen, Obra citada, págs. 126, notas 4 y 5 : "This is nor unlikely since we know that merchants had connections both in Ostia and Rome and that some important people had offices in the city as well as in the harbour town"; BECATTI, Mitrei Ostia, págs. 59 SS. 
orientales y habiendo ya asumido directamente el Estado la gestión de la economía en todo el imperio.

Todavía se registrará ese mitraismo residual al que antes nos referimos, representado por los últimos monumerosos mitraicos dedicados al Dios Invicto por laetes o limitanei renanos y danubianos, asentados en la zona $\mathrm{N}$ de la Península a finales del siglo III e inicios del siglo IV.

Y por último también podemos suponer en Hispania la existencia de una última fase del mitraismo en la clandestinidad, como ocurriría en otras partes del Imperio y en la misma Roma hasta el siglo $v^{95}$.

El caso de Hispania, desde el punto de vista de esta religión, es, en parte, análogo al de otras provincias del Imperio en las que, como ya hemos apuntado, no fueron los elementos militares, sino los civiles y urbanos, especialmente los comerciantes greco-orientales, los introductores, organizadores y difusores de este culto. En tal sentido, el caso de Hispania sería paralelo al de la Galia, en donde, como también hemos señalado, se evidencia un protagonismo de los elementos mercantiles en este fenómeno cultual.

En Hispania el mitraismo también parece haber sido la expresión de una moda de la época, la de la orientalización del imperio romano. Quizás por ello careció posiblemente de una verdadera base étnico-demográfica, y sus testimonios arqueológicos no aportan indicaciones precisas sobre el verdadero origen de sus devotos. Sin embargo, a diferencia de otras provincias, el mitraismo hispano sí aporta importantes indicaciones que evidencian plenamente sus caracteres especificos y su desenvolvimiento principal en un contexto mercantil de origen oriental.

${ }^{95}$ Cfr. A. Yelo, "Supervivencia del culto solar en la Roma de León Magno", Memorias de Historia Antigua, V (1981), págs. 243-246. 